\title{
Anterior mitral valve aneurysm perforation in a patient with preexisting aortic regurgitation
}

\section{Perforazione di aneurisma del lembo mitralico anteriore in un paziente con preesistente rigurgito aortico}

\author{
Rodolfo Citro, Angelo Silverio, Roberto Ascoli, Antonio Longobardi, \\ Eduardo Bossone, Giuseppe Di Benedetto, Federico Piscione
}

\begin{abstract}
Anterior mitral valve aneurysm perforation in a patient with preexisting aortic regurgitation. $R$. Citro, A. Silverio, R. Ascoli, A. Longobardi, E. Bossone, G. Di Benedetto, F. Piscione.

We report the case of a 71-year-old man hospitalized for acute heart failure. Transthoracic and transesophageal echocardiography showed mitral valve aneurysm (MVA) rupture and severe mitral regurgitation. No vegetations but significant aortic regurgitation were also observed. MVA perforation is a rare life-threatening condition that typically
\end{abstract}

occurs as a complication of endocarditis but may also be associated with other diseases, in particular connective tissue disorders. In the present case, the absence of such etiology suggests a possible role for of aortic regurgitation in MVA rupture secondary to a "jet lesion" mechanism.

Keywords: mitral valve aneurysm, mitral regurgitation, aortic regurgitation.

Monaldi Arch Chest Dis 2012; 78: 210-211.

Heart Department, University Hospital “San Giovanni di Dio e Ruggi d'Aragona”, Salerno, Italy.

Corresponding author: Rodolfo Citro, MD, FESC; University Hospital "San Giovanni di Dio e Ruggi d'Aragona"; Heart Tower Room 810; Largo Città di Ippocrate, I-84131 Salerno, Italy; Phone: +39 089 673377; Tel: +39 0332278934 ; Fax: +39 033239 3309; Mobile+393473570880; E-mail address: rodolfocitro@gmail.com

\section{Case report}

A 71-year-old man with a history of prostatic cancer and without reported fever in the previous weeks was admitted to our department for increasing dyspnea. He was restless and preferred to remain sitting up in bed. Cardiac auscultation revealed a 4/6 holosystolic murmur at the apex radiating to the axilla. Chest percussion revealed dull sounds and rales upon auscultation of the lungs. No skin lesions were detected. Blood arterial pressure was $90 / 55 \mathrm{mmHg}$, heart rate 130 beats per minute, and respiratory rate 40 breaths per minute. Hemogasanalysis revealed hypoxemia and respiratory acidosis $\left(\mathrm{pH}=7,2 ; \mathrm{pO}_{2}=\right.$ $55 \mathrm{mmHg} ; \mathrm{pCO}_{2}=52 \mathrm{mmHg}$ ). Troponin I was in the normal range, whereas $\mathrm{B}$-type natriuretic peptide concentration was elevated $(960 \mathrm{pg} / \mathrm{ml})$. White blood cell count as well as inflammation laboratory indexes were not altered. Blood cultures were negative. No significant ST-T changes were observed on ECG. Chest X-ray revealed bilateral and diffuse fluffy shadows with minimal visualization of the normal lung fields that confirmed the diagnosis of pulmonary edema. Real-time three-dimensional transthoracic echocardiography (RT-3D TTE) in the surgeon's view showed an aneurysm of the anterior mitral leaflet with severe mitral regurgitation (Fig. 1). Left ventricular enlargement (left ventricular end-diastolic volume $=140 \mathrm{ml} / \mathrm{m}^{2} ;$ n.v. $<75 \mathrm{ml} / \mathrm{m}^{2}$ ) with mildly reduced systolic function (ejection fraction $=44 \%$ ) were also detected. Color flow mapping of the aortic root showed moderate aortic regurgitation. The left atrium was enlarged $(49 \mathrm{~mm})$. Pulmonary artery systolic pressure derived from the peak velocity of tricuspid regurgitation was elevated $(63 \mathrm{mmHg})$. The right chambers were within normal limits, and the tricuspid annular plane systolic excursion was normal $(31 \mathrm{~mm})$. Perforation of the mitral valve aneurysm (MVA) causing mitral regurgitant jet was clearly appreciated during two-dimensional transesophageal echocardiography (TEE) (Fig. 2). In addition, the long-axis view showed a wide and eccentric aortic regurgitant jet directed towards the anterior mitral leaflet (Fig. 2). Having a life expectancy of more than one year (Eastern Cooperative Oncology Group grade =1), the patient was referred for surgery. Mitral and aortic valves were replaced with a Carpentier-Edwards bioprosthesis ( $25 \mathrm{~mm}$ and $21 \mathrm{~mm}$, respectively). Despite inotropic support after 24 hours the patient died of pump failure.

\section{Discussion}

MVA is a rare finding that typically occurs as a complication of aortic valve endocarditis but may also be associated with other diseases, in particular connective tissue disorders (e.g., Marfan syndrome, Barlow syndrome, osteogenesis imperfecta and pseudoxanthoma elasticum) [1]. In the absence of other possible causes, aortic regurgitation has previously been related to MVA development [2, 3]. 


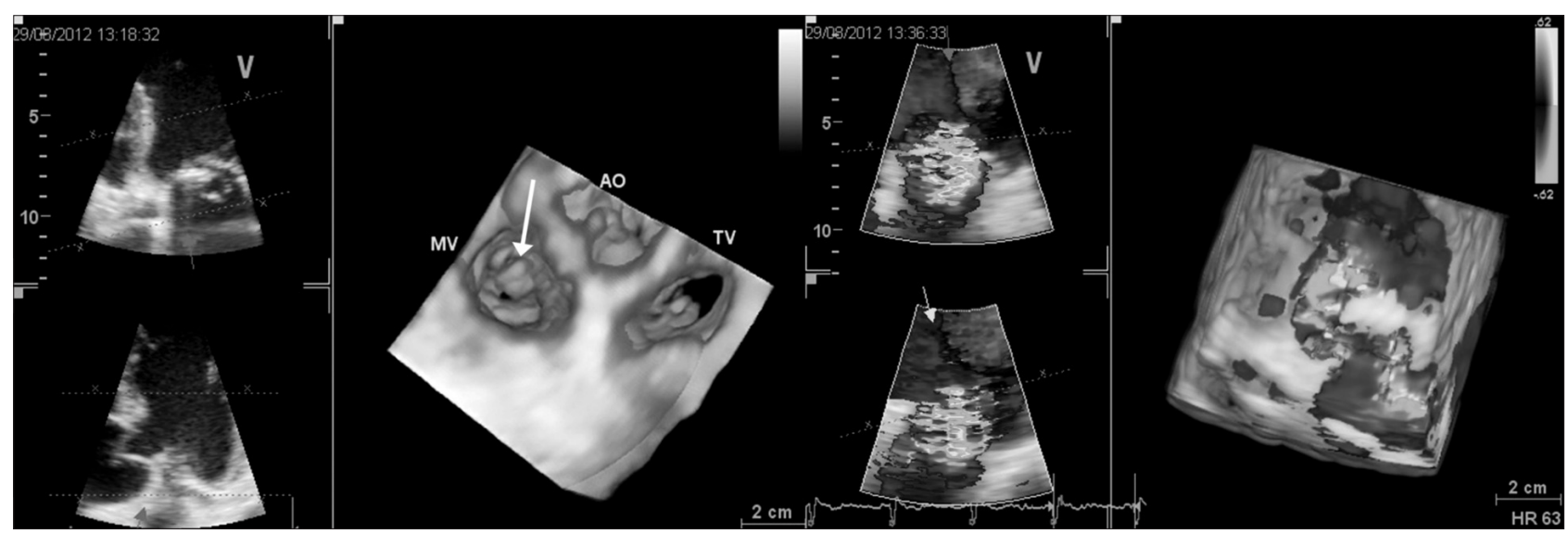

Figure 1. - Real-time three-dimensional transthoracic echocardiography of the mitral valve in the surgeon's view: the aneurysm of the anterior mitral leaflet (left panel, see arrow) and severe mitral regurgitation (right panel) can be clearly appreciated. (Ao = Aorta; MV = Mitral valve; TV = Tricuspid valve).

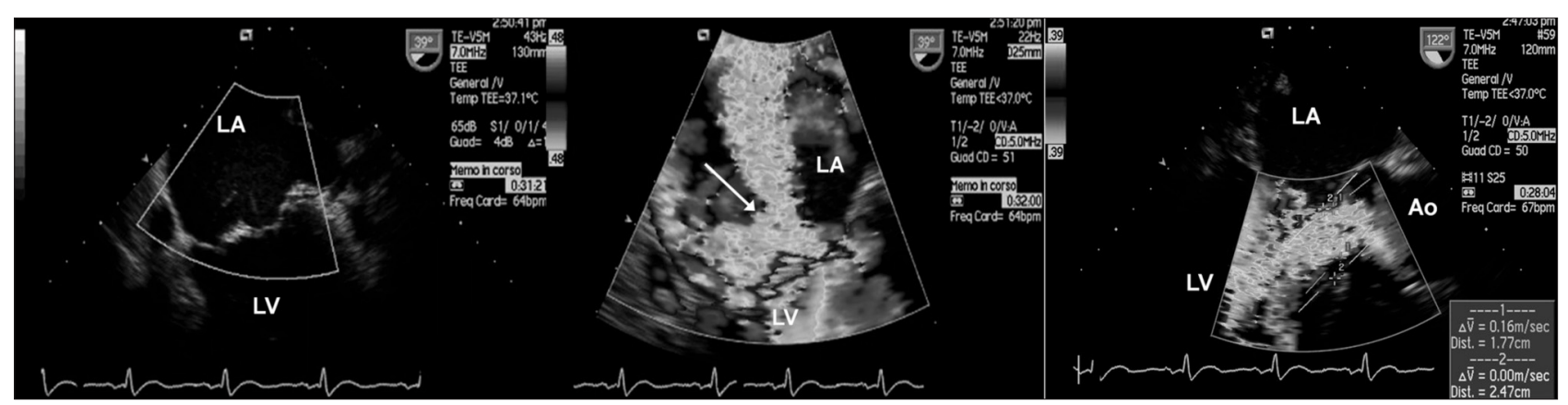

Figure 2. - Midesophageal two-chamber view at $39^{\circ}$ showing perforation of the mitral valve annulus (left panel, see arrow) with a regurgitant jet through the ruptured mitral valve annulus (central panel, see arrow). Midesophageal long-axis view of the left ventricle with ascending aorta: a severe aortic regurgitant jet directed towards the left anterior mitral leaflet can be visualized (right panel). (Ao = Aorta; LA = Left atrium; LV = Left ventricle).

MVA may result from a "jet lesion" mechanism of the regurgitant aortic flow that impacts the anterior (more frequently) or posterior mitral leaflets. RT-3D TTE evaluation appears useful to better define the anatomical features of MVA. However, TEE still remains an essential tool for a comprehensive assessment of the mitral apparatus, allowing accurate identification of the origin and severity of mitral regurgitation. Additionally, in our patient, TEE detection of the aortic regurgitant jet directed towards the anterior mitral leaflet reinforces the hypothesis of a "flow-dependent" mitral valve lesion [2].

MVA perforation is a possible catastrophic complication that precipitates rapid deterioration of the hemodynamic status. Acute heart failure may be the first clinical presentation of a previously unrecognized MVA [4]. This clinical condition requires urgent surgical valve replacement or repair, especially in patients with preexisting aortic regurgitation and left ventricular systolic dysfunction.

\section{Riassunto}

Riportiamo il caso di un uomo di 71 anni ricoverato per insufficienza cardiaca acuta. L'ecocardiografia transtoracica e transesofagea ha documentato un'aneurisma della valvola mitrale perforato con insufficienza mitralica severa. Non sono state osservate vegetazioni ma solo l'associazione con insufficienza aortica significativa. La perforazione di un'aneurisma della valvola mitrale è una rara condizione pericolosa per la vita che in genere si verifica come complicanza di endocardite ma può essere associata anche con altre malattie, specie quelle del tessuto connettivo. Nel presente caso, l'assenza di tali patologie suggerisce un possibile ruolo dell' insufficienza aortica nella genesi della rottura dell' aneurisma della valvola mitrale dovuto ad un meccanismo di lesione indotta "dal jet rigurgitante".

\section{ABBREVIATIONS AND ACRONYMS}

MVA: mitral valve aneurysm

ECG: electrocardiography

RT-3D TTE: real-time three-dimensional transthoracic echocardiography

TEE: transesophageal echocardiography

\section{References}

1. Vilacosta I, San Román JA, Sarriá C, et al. Clinical, anatomic, and echocardiographic characteristics of aneurysms of the mitral valve. Am J Cardiol 1999 Jul; 84(1): 110-3.

2. Cai TH, Moody JM Jr, Sako EY. Mitral valve aneurysm due to severe aortic valve regurgitation. Circulation 1999 Sep; 100(12): e53-6.

3. Ono T, Iwaya F, Igari $\mathrm{T}$, et al. A case report of perforated aneurysm of mitral valve with aortic regurgitation. Kyobu Geka 1991 Oct; 44(11): 953-6.

4. Tewari S, Moorthy N, Sinha N. Ruptured mitral valve aneurysm: an uncommon cause of acute dyspnoea. Echocardiography 2010 Nov; 27(10): E119-21. 